\title{
The Impact of Low Self-Control on Online Harassment: Interaction with Opportunity.
}

Hyunin Baek

University of Louisville, Kentucky, USA.

Michael M. Losavio

University of Louisville, Kentucky, USA.

George E. Higgins

University of Louisville, Kentucky, USA.

Follow this and additional works at: https://commons.erau.edu/jdfsl

Part of the Computer Engineering Commons, Computer Law Commons, Electrical and Computer Engineering Commons, Forensic Science and Technology Commons, and the Information Security Commons

\section{Recommended Citation}

Baek, Hyunin; Losavio, Michael M.; and Higgins, George E. (2016) "The Impact of Low Self-Control on Online Harassment: Interaction with Opportunity.," Journal of Digital Forensics, Security and Law: Vol. 11 : No. 3 , Article 6.

DOI: https://doi.org/10.15394/jdfsl.2016.1417

Available at: https://commons.erau.edu/jdfsl/vol11/iss3/6

This Article is brought to you for free and open access by

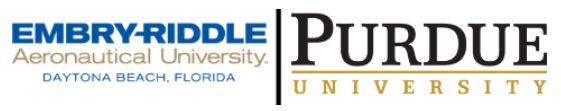
the Journals at Scholarly Commons. It has been accepted for inclusion in Journal of Digital Forensics, Security and Law by an authorized administrator of Scholarly Commons. For more information, please contact commons@erau.edu.

(c)ADFSL 


\title{
THE IMPACT OF LOW SELF-CONTROL ON ONLINE HARASSMENT: INTERACTION WITH OPPORTUNITY
}

\author{
Hyunin Baek \\ University of Louisville \\ Kentucky, USA \\ Michael M. Losavio \\ University of Louisville \\ Kentucky, USA \\ George E. Higgins \\ University of Louisville \\ Kentucky, USA
}

\begin{abstract}
Developing Internet technology has increased the rates of youth online harassment. This study examines online harassment from adolescents with low self-control and the moderating effect of opportunity. The data used in this study were collected by the Korea Institute of Criminology in 2009. The total sample size was 1,091. The results indicated that low self-control, opportunity, and gender have a significant influence on online harassment. This study also showed a moderating effect of opportunity with low self-control on online harassment. However, these results differed according to gender; for males, low self-control and opportunity significantly impacted online harassment; for females, however, only low self-control significantly impacted online harassment. Furthermore, the interaction between low self-control and opportunity did not significantly influence online harassment for either gender. The results of multiple regression strongly supported Gottfredson and Hirschi's (1990) theory, but other models divided by gender only partially supported interacting effects. Thus, low self-control theory should be applied by genders. These results can help to guide investigations of online misconduct and application of digital forensics resources as well as suggest policies and practices to prevent and remediate it.
\end{abstract}

Keywords: online harassment, low self-control, opportunity, time control, interaction

\section{INTRODUCTION}

Online harassment is defined as a problematic behavior on the Internet that includes threats to assault or harm, as well as efforts to embarrass or humiliate (Finkelhor, Mitchell, \& Wolak, 2000). Youth who have experienced online harassment suffer from a variety of negative consequences such as psychological distress (Finkelhor et al., 2000; Ybarra, 2004; Ybarra \& Mitchell, 2004) and suicidal ideation
(Van Geel, Vedder, \& Tanilon, 2014). Finn (2004) found that $10 \%$ to $15 \%$ of college students in her study have experienced online harassment. According to a national survey (Jones, Mitchell, \& Finkelhor, 2013), the rates of youth online harassment have increased from $6 \%$ in 2000 to $11 \%$ in 2010 . One-third of youth who have been the target of online harassment in the previous year felt depressive symptoms (Finkelhor et al., 2000). Despite growing concerns about online harassment, 
many studies have only concentrated on victimization in online harassment (Finkelhor et al., 2000; Wolak, Mitchell, \& Finkelhor, 2006; Ybarra, Mitchell, Wolak, \& Finkelhor, 2006).

Not only did the victims display distress symptoms, but also the perpetrators of online harassment were associated with these symptoms (Fenaughty \& Harré, 2013). Furthermore, online harassers were linked to various social problems such as online aggressive behavior (Ybarra et al., 2006), substance use, and offline delinquency (Ybarra \& Mitchell, 2004). Much research has examined the socially problematic behaviors on the Internet: for instance, harassment (Khunrana, Bleakley, Jordan, Romer, 2015), pornography (Buzzell, Foss, \& Middleton, 2006), and software piracy (Higgins, 2006). Increasing technology use makes more opportunities of deviant behaviors on the computer and the Internet (Donner, Marcum, Jennings, Higgins, \& Banfield, 2014; Power, 2000; Rogers, Smoak, \& Liu, 2006; Ziyanak, 2014), such as the development of virus ware, cyber terrorism, computer hacking, online harassment, and certain self-harm behaviors (Giles, 2006; Joinson, 2005). As to these forms of online deviance, Gottfredson and Hirschi's (1990) self-control theory has provided a useful theoretical framework (Donner et al., 2014). Many studies have shown the association between criminological theory and online deviance and crime: for example, software piracy (Higgins, 2005; Moon, McCluskey, McCluskey, \& Lee, 2012), internet pornography (Buzzell et al., 2006), and various types of cyber deviance such as harassment and hacking (Holt, Bossler, \& May, 2012).

\section{THEORETICAL BACKGROUND}

To explain the causes of delinquent behaviors and crime, Gottfredson and Hirschi (1990) proposed a general theory of crime based on low self-control. This theory described individuals with low levels of self-control as being "impulsive, insensitive, physical (as opposed to verbal), risking, short-sighted, and nonverbal" (Gottfredson \& Hirschi, 1990, p 90). Gottfredson and Hirschi (1990) assumed that individuals have rational decision-making processes to explain why they either commit or refrain from crime. Using concepts of low selfcontrol, many studies have demonstrated various deviances and crimes: imprudent behavior (Arneklev, Grasmick, Tittle, \& Bursik, 1993), academic dishonesty (Cochran, Wood, Sellers, Wilkerson, Chamlin, 1998), problem behavior (Fletcher, Steinberg, \& Williams-Wheeler, 2004), bullying (Moon, Hwang, \& McCluskey, 2011), substance use (Desmond, Bruce, \& Stacer, 2012), and police misconduct (Donner \& Jennings, 2014).

Furthermore, Gottfredson and Hirschi (1990) suggested that individuals with low selfcontrol are more likely to engage in various types of deviant and criminal behaviors than those with high self-control, especially when presented with opportunity (Gottfredson \& Hirschi, 1990). As a result, individuals who are impulsive, insensitive, short-sighted, and risk taking are less likely to resist the opportunity to commit crime (Gottfredson \& Hirschi, 1990). Prior studies have shown the results of the associations between self-control and opportunities on deviant behaviors and crime (LaGrange \& Silverman, 1999; Moon \& Alarid, 2015; Seipel \& Eifler, 2010; Smith, 2004).

Nevertheless, opportunity in self-control theory has been examined less than self-control to find causes of crime (Hey \& Forrest, 2008; Desmond et al, 2012; Seipel \& Eifler, 2010; Smith, 2004). Gottfredson and Hirschi did not explain the precise definition of opportunity (Seipel \& Eifler, 2010). Furthermore, Higgins and Ricketts (2004) claimed that the role of opportunity is uncertain in Gottfredson and 
Hirschi's theory, and they showed that opportunities did not mediate the relationship between low self-control and academic dishonesty. One meta-analysis (Pratt \& Cullen, 2000) found that opportunity did not work well as a moderating predictor of deviance and crime.

Despite mixed results about the role of opportunity in self-control theory, many researchers have found the positive impact of a relationship between low self-control and opportunity on deviance and crime (LaGrange \& Silverman, 1999; Longshore \& Turner, 1998; Moon \& Alarid, 2015; Seipel \& Eifler, 2010; Smith, 2004). Specifically, Moon and Alarid (2015) asserted that opportunity in their study was a more explainable factor for bullying than low self-control. Currently, general theory of crime (Gottfredson \& Hirschi, 1990) has been applied to various forms of online deviance and cybercrime (Buzzell et al., 2006; Donner et al., 2014; Higgins, 2005, 2006; Higgins, Fell, \& Wilson, 2006, 2007; Higgins, Wolfe, \& Marcum, 2008; Holt et al., 2012; Kim \& Kim, 2014; Moon, McCluskey, \& McCluskey, 2010; Moon et al., 2012). Donner et al. (2014) supported the link between low self-control and various online behaviors such as threatening/insulting others through email or instant messaging, hacking into an unauthorized area of the internet, and using someone else's personal information on the internet without his/her permission. Higgins et al. (2007) indicated that individuals with low self-control are more likely to commit digital piracy than those with high self-control. This connection between low self-control and digital piracy was consistent with the previous research (Higgins, 2005, 2006; Higgins et al, 2006). Using the Korean Youth Panel Survey data, Kim and Kim (2014) investigated the association between self-control and computer piracy with time spent on computers among Korean adolescents. The results strongly support Gottfredson and Hirschi's theory; adolescents with high self-control were less likely to commit on-line software piracy.

Buzzell et al. (2006) found that low selfcontrol was related to pornography use, and gender was the most significant factor to Internet behaviors. The factors in the study, downloading pornography and visiting pornographic websites, were explained by gender, low self-control, and opportunities. Moon et al. (2012) found that illegal use of other's resident registration number was explained by self-control theory. Gender, low self-control, and opportunity had a significant impact on this illegal use. However, Moon et al. (2012) showed different results from the theory's hypothesis; for example, "low selfcontrol in male and female models is not a significant predictor of illegal downloading of software" (p. 474). Regarding low self-control to explain gender differences, many researchers found mixed results (Higgins, 2006). Longshore, Turner, and Stein (1996) claimed that low self-control should not explain gender differences for offenses. However, Tittle, Ward, and Gramick (2003) showed that low selfcontrol could account for gender differences. Moon et al. (2012) found some factors about opportunity differently impacted illegal downloading between genders. For example, hours of computer usage increase illegal downloading for boys, while the opportunity factor did not have any significant effect for girls (Moon et al., 2012).

\section{PURPOSE OF STUDY}

The purpose of this study is to test the general theory of crime applied to online harassment, to see if adolescents with low self-control will be more likely to commit online harassment than those with high self-control. This study also examined the moderating effects between 
low self-control and opportunity as well as gender differences on online harassment. The general theory of crime suggested that individuals with low self-control are more likely to engage in various types of deviant and criminal behaviors than those with high selfcontrol, especially when presented with opportunity. Thus, the lower self-control and the more opportunities adolescents have, the more likely they may commit online harassment. This study also analyzes how gender differences with self-control and opportunity impact online harassment. This may serve to guide policymakers, computer crime investigators and digital forensics examiners as to the scope of investigations where further misconduct are indicated and remedial practices that may serve to prevent misconduct, particularly by young people.

\section{METHOD}

\subsection{Data}

The data used in this study were collected by the Korea Institute of Criminology (KIC) in 2009, a one-time cross-sectional study (collection period from August 28 2009 to September $\left.11^{\text {th }} 2009\right)$. The data were compiled from self-report surveys collected from elementary and middle school students through stratified cluster sampling in Seoul, the capital city of Korea (Choi, 2009). The purpose of the original data was an evaluation of the level of awareness of cybercrime law and development of a cybercrime prevention program for the Elementary Education Act. The main research contents were ethics information on cybercrime, cybercrime-related legal knowledge, awareness of cybercrime victims, cybercrime damage experience, computer-related ties and conflict with parents, and the number of peers engaged in cybercrime (Choi, 2009). The data were donated to the Korean Social Science Data Archive in 2014 (data code: A1-20090119), which is a non-profit social science data archive integrating the Korean Social Science Library and the Korean Social Survey Data Archive. The total sample size was 1,091. Of these, $505(46.3 \%)$ were female and 586 $(53.7 \%)$ were male. The ages of respondents were between 11 and 15 ; the grades were $5^{\text {th }}$ to $6^{\text {th }}$ in elementary, and $1^{\text {st }}$ in middle school.

\subsection{Measures}

This study defined online harassment as problematic behaviors on the Internet that frighten someone through abuse or aggressive language, including threats to assault or harm as well as efforts to embarrass or humiliate (Finkelhor et al., 2000). For example, this study used as a dependent variable, the item "when I played computer game or did Internet, I have frightened someone by abuse or aggressive language." The item measured as "how many times you have experienced." One independent variable was low self-control as defined by Gottfredson and Hirschi's (1990): low self-control is "impulsive, insensitive, physical (as opposed to verbal), risking, shortsighted, and nonverbal" (p. 90). This study used four items $(\alpha=.80)$ related to this definition: 'I tend to do my job without a plan,' 'I always act on a whim,' 'I behave impulsively in many cases,' and 'I behave as soon as possible no matter what happen later.' The answer was coded from ' $1=$ never' to ' $5=$ always'. Another independent variable was opportunity, 'my parent has a strict time rule about computer use, so I can only use computer during that time period,' and the respondents used an answer choice (' $1=$ never' to ' $5=$ always'). Regarding gender, this study coded as 'female $=0$ ' and 'male $=1$ '.

\subsection{Analysis}

Using the 2009 data of the Korean Institute of Criminology (KIC) (Choi, 2009), this study conducted data analyses through the following steps. The first analysis involved a descriptive statistic for examining mean, standard 
deviation, skewness, and kurtosis. Second, this study conducted a bivariate statistic, looking at correlations between online harassment, low self-control, and opportunity (time control by parents). To test the hypothesis that low selfcontrol and opportunity influence online harassment, this study conducted multiple regressions. This was the third step. A final step examined the interaction analysis between low self-control and opportunity as well as gender differences.

\section{RESULTS}

\subsection{Descriptive Statistic}

The average values of the variables that were used in this study [online harassment, low selfcontrol, and opportunity (time control by parent)] as well as their standard deviations, maximum and minimum values, skewness, and kurtosis can be seen in Table1. The descriptive statistics showed that the online harassment measure had a mean of 2.65 and a standard deviation $(S D)$ of 6.23 (skewness $=2.77$ and kurtosis $=6.67)$. Regarding the independent variables, the mean of low self-control was 9.77 $(S D=3.50$, skewness $=0.27$, and kurtosis $=$ $0.04)$ and opportunity $2.97 \quad(S D=1.37$, skewness $=0.04$, and kurtosis $=-1.23)$. Almost $53 \%$ of sample was male.

\subsection{Bivariate Statistic}

A bivariate correlation analysis was performed to identify the relationships between the variables. Regarding online harassment, all three variables were positively related to each other. Especially, low self-control was significantly associated with online harassment $(\mathrm{r}=.21, \mathrm{p}<.01)$. Furthermore, all correlations between online harassment and others were significant: opportunity $(\mathrm{r}=.09, \mathrm{p}$ $<.01)$ and gender $(\mathrm{r}=.23, \mathrm{p}<.01)$. The correlation between low self-control and opportunity was also a positive association ( $\mathrm{r}$ $=.10, \mathrm{p}<.01)$. In the association with opportunity and gender $(\mathrm{r}=-.12, \mathrm{p}<.01)$, there was a negative correlation. On the other hand, there was no relationship between low self-control and gender, as shown in Table 2.

Table 1

Sample Descriptive Statistics

\begin{tabular}{|cccccccc|}
\hline Variables & Valid N & Mean & SD & Min & Max & Skewness & Kurtosis \\
\hline Online harassment & 1028 & 2.65 & 6.23 & 0 & 25 & 2.77 & -0.67 \\
Low self-control & 1070 & 9.77 & 3.50 & 4 & 20 & 0.27 & 0.04 \\
Opportunity & 1086 & 2.97 & 1.37 & 1 & 5 & -1.23 \\
Gender & 1091 & 0.53 & 0.50 & 0 & 1 & -0.15 & -1.98 \\
\hline
\end{tabular}

Note. $\mathrm{N}=1,091$ 
Table 2

Correlation Matrix

\begin{tabular}{|l|l|l|l|l|}
\hline Variables & 1 & 2 & 3 & 4 \\
\hline Online harassment & - & & & \\
\hline Low self-control & $.207^{* *}$ & - & - & \\
\hline Opportunity & $.087^{* *}$ & $.096^{* *}$ & $-.120^{* *}$ & - \\
\hline Gender & $.228^{* *}$ & -.034 & & \\
\hline
\end{tabular}

Note. ${ }^{*} \mathrm{p}<.05,{ }^{* *} \mathrm{p}<.01$

\subsection{Multivariate Statistics}

To determine which independent variables (low self-control, opportunity, and gender) were the predictors of online harassment as a dependent variable, this study conducted a multiple regression to Model 1. Regression results indicated an overall model of three predictors (low self-control, opportunity, and gender) that significantly predict online harassment $\left(\mathrm{R}^{2}=.11, \mathrm{R}_{\text {adj }}^{2}=.11, \mathrm{~F}_{(2,1002)}=\right.$ $40.39, \mathrm{p}<.001)$. That is, low self-control, opportunity, and gender accounted for $11 \%$ of variance in online harassment. This results support Gottfredson and Hirschi (1990)'s theory. There were no problems of multicollinearity within independent variables because all tolerance was above .20 and VIF was below 4.0 (O'Brien, 2007). The results of multiple regression also showed that low selfcontrol $(\mathrm{b}=.36, \mathrm{t}=6.80)$; opportunity $(\mathrm{b}=$ $.45, \mathrm{t}=3.27)$; and gender $(\mathrm{b}=3.06, \mathrm{t}=8.17)$ were positively related to online harassment. Among independent variables in Model 1, gender was the most significant factor to online harassment $(\beta=.25)$ compared to low selfcontrol $(\beta=.20)$ and opportunity $(\beta=.10)$. A summary of the regression is presented in Table 3.

Table 3

Multiple Regressions

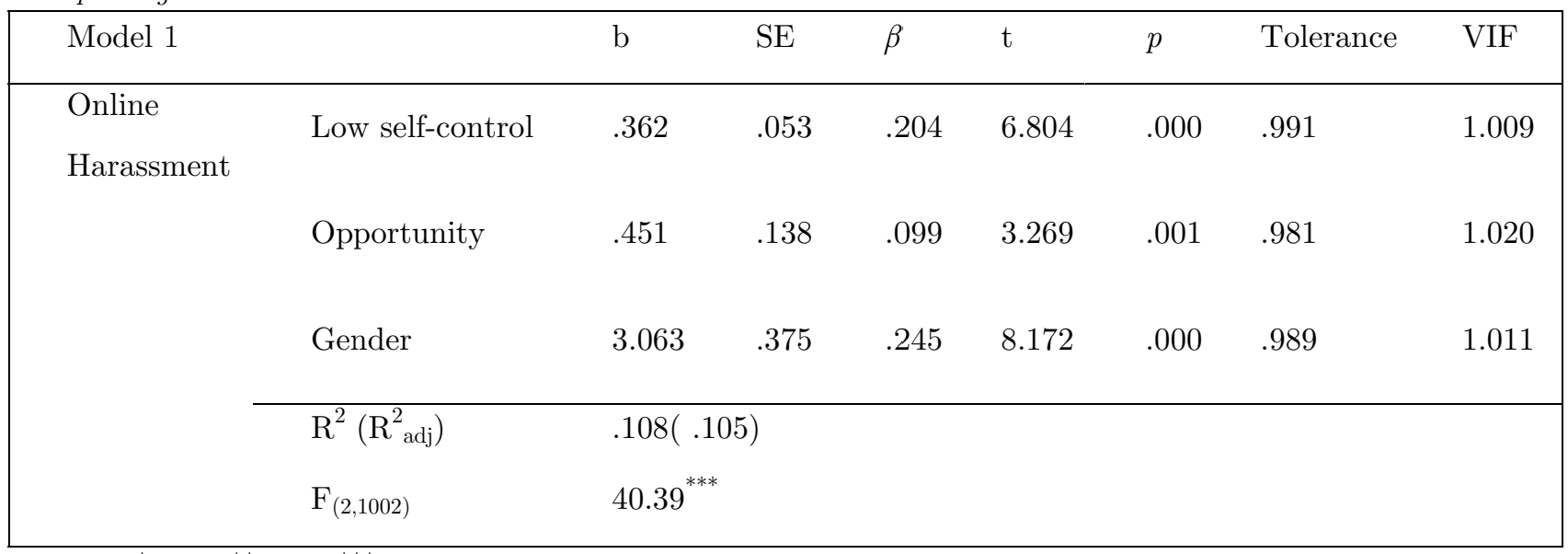

Note. ${ }^{*} \mathrm{p}<.05,{ }^{* *} \mathrm{p}<.01,{ }^{* * *} \mathrm{p}<.001$ 


\subsection{Alternative Analysis}

This study also conducted alternative statistical analyses in order to examine moderating effects between low self-control and opportunity. In Model 2, regression results indicated that an overall model of four predictors (variables in Model 1 including the interaction between low self-control and opportunity) statistically significantly predicted online harassment $\left(\mathrm{R}^{2}=.11, \mathrm{R}_{\text {adj }}^{2}=\right.$ $\left..11, \mathrm{~F}_{(3,1001)}=31.86, \mathrm{p}<.001\right)$. There were no problems of multi-collinearity within independent variables because all tolerances were above .20 and VIF was below 4.0 (O'Brien, 2007).
The results of multiple regression also showed that low self-control $(\mathrm{b}=.36, \mathrm{t}=$ $6.82)$; opportunity $(\mathrm{b}=.47, \mathrm{t}=3.38)$; gender $(\mathrm{b}=3.06, \mathrm{t}=8.19)$; and interaction between low self-control and opportunity $(\mathrm{b}=.09, \mathrm{t}=$ 2.39) were positively related to online harassment. That is, low self-control, opportunity, gender, and interaction accounted for $11 \%$ of variance in online harassment. In Model 2, the gender was also the most significant factor to online harassment $(\beta=$ $.25)$, compared to low self-control $(\beta=.20)$, opportunity $(\beta=.10)$, and interaction $(\beta=$ $.07)$. A summary of the regression is presented in Table 4.

Table 4

Multiple Regressions with the Interaction Effect

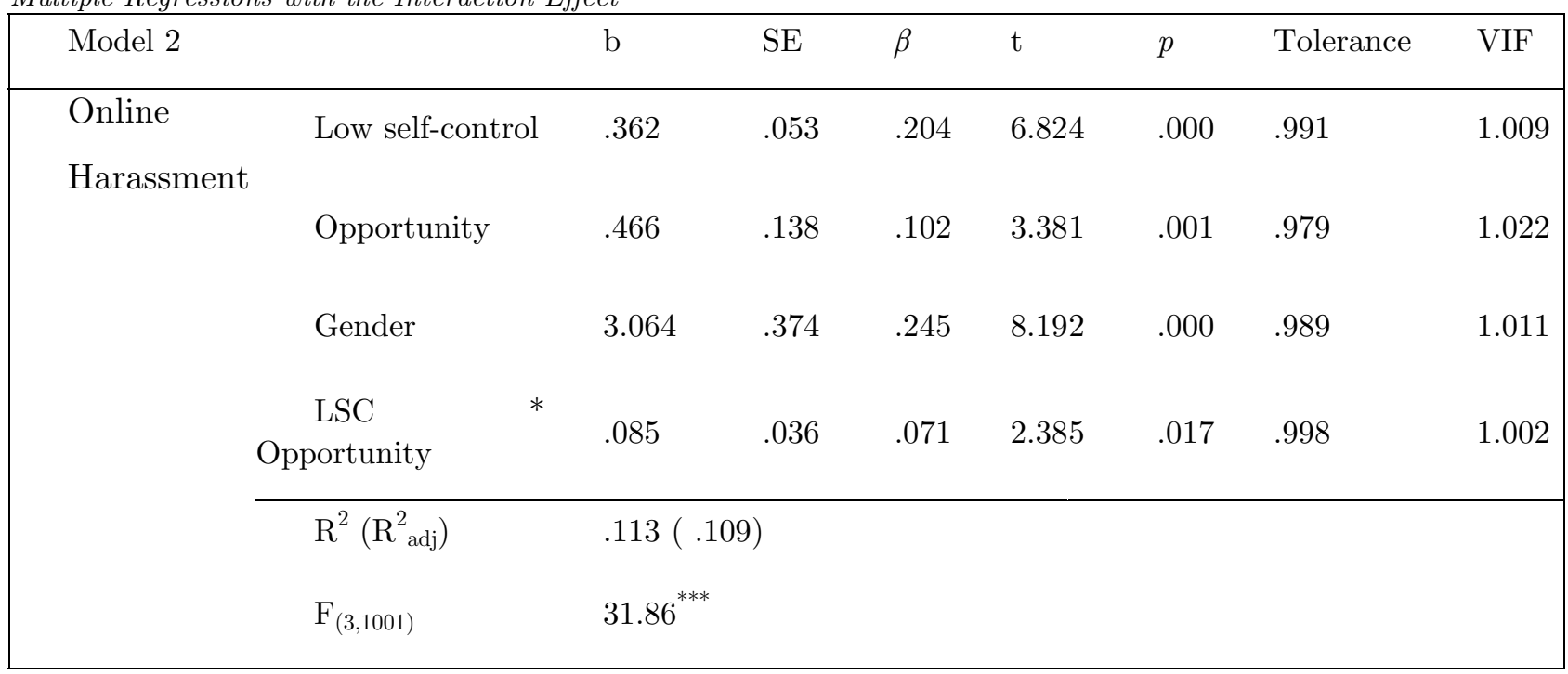

Note. ${ }^{*} \mathrm{p}<.05,{ }^{* *} \mathrm{p}<.01,{ }^{* * *} \mathrm{p}<.001$

To show the effect of the interaction between low self-control and opportunity, this study generated a bar graph showing different mean levels of online harassment. Following previous studies (Gibson \& Wright, 2001; Piquero \& Tibbetts, 1999; Raine, Brennan, \& Mednick, 1994), this study created a fourcategory variable. Based on their mean scores, the measures of low self-control and opportunity were dichotomized. Therefore, scores below the mean indicated higher selfcontrol (HSC) and lower opportunity (LO) in online harassment, while scores above the mean indicated lower self-control (LSC) and higher opportunity (HO) in online harassment. The four-category variable was labeled as category 0 to 3 : 1 ) category 0 represented higher self-control and lower opportunity (HSC-LO, $\mathrm{n}=214$ ); 2) category 1 represented higher self-control and higher opportunity 
(HSC-HO, $\mathrm{n}=257$ ); 3) category 2 represented lower self-control and lower opportunity (LSCLO, $\mathrm{n}=190)$; and 4) category 3 represented lower self-control and higher opportunity (LSC-HO, $\mathrm{n}=344$ ). The results show in Figure 1. The highest mean level of online harassment was category 3 (lower self-control and higher opportunity, mean $=4.10$ ). Thus, adolescents with low self-control and high opportunity had a considerably higher mean score on online harassment.

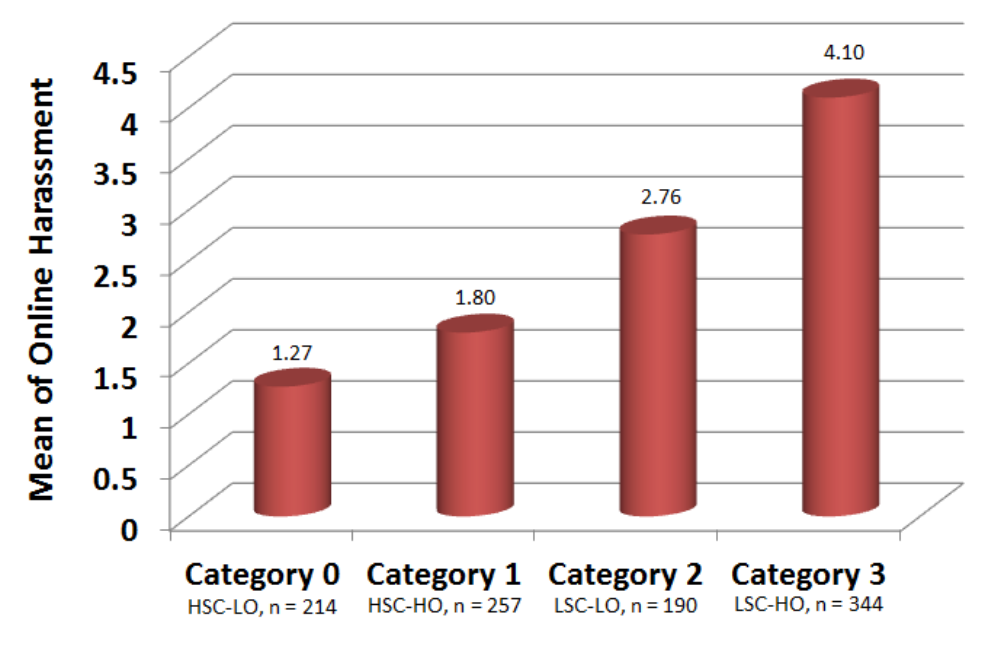

Figure 1. Mean Level of Online Harassment for Interaction Group

To determine which independent variables (low self-control, opportunity, and interaction) were the predictors of online harassment as a dependent variable by gender, this study conducted a multiple regression to Model 3 and 4. In Model 3 for males, regression results indicated an overall model of three predictors (low self-control, opportunity, and interaction) that significantly predict online harassment $\left(\mathrm{R}^{2}=.08, \mathrm{R}_{\text {adj }}^{2}=.07, \mathrm{~F}_{(3,517)}=14.92, \mathrm{p}<\right.$ $.001)$. That is, low self-control, opportunity, and their interaction accounted for $8 \%$ of variance in online harassment for males. There were no problems of multi-collinearity within independent variables because all tolerances were above .20 and VIF was below 4.0 (O'Brien, 2007). The results of multiple regression also showed that low self-control (b $=.48, \mathrm{t}=5.18)$ and opportunity $(\mathrm{b}=.82, \mathrm{t}=$
3.41) were positively related to online harassment for males. However, the interaction between low self-control and opportunity was not significantly related to online harassment for males. Among independent variables in Model 3, low self-control was the most significant factor to online harassment $(\beta=$ $.22)$ compared to opportunity $(\beta=.15)$. A summary of the regression is presented in Table 5.

In Model 4 for females, regression results indicated an overall model of three predictors (low self-control, opportunity, and interaction) that significantly predict online harassment $\left(\mathrm{R}^{2}=.06, \mathrm{R}_{\text {adj }}^{2}=.05, \mathrm{~F}_{(3,480)}=9.85, \mathrm{p}<\right.$ $.001)$. That is, low self-control, opportunity, and interaction accounted for $6 \%$ of variance in online harassment for females. There were no problems of multi-collinearity within 
independent variables because all tolerances were above .20 and VIF was below 4.0. The results of multiple regression also showed that only low self-control $(\mathrm{b}=.24, \mathrm{t}=4.98)$ was positively related to online harassment for females. However, opportunity and the interaction between low self-control and opportunity were not significantly related to online harassment for females. Therefore, for one-unit increase in low self-control, there was .24 change in online harassment for females. In Model 4 for females, only low self-control was a significant factor to online harassment $(\beta=$ $.22)$. A summary of the regression is presented in Table 6 .

Table 5

Multiple Regressions with the Interaction Effect for Males

\begin{tabular}{|c|c|c|c|c|c|c|c|c|}
\hline Model 3 & & $\mathrm{~b}$ & $\mathrm{SE}$ & $\beta$ & $\mathrm{t}$ & $p$ & Tolerance & VIF \\
\hline Online & Low self-control & .476 & .092 & .220 & 5.179 & .000 & .991 & 1.009 \\
\hline \multicolumn{9}{|c|}{ Harassment } \\
\hline & Opportunity & .819 & .240 & .145 & 3.412 & .001 & .991 & 1.009 \\
\hline & LSC * Opportunity & .104 & .064 & .069 & 1.628 & .104 & 1.000 & 1.000 \\
\hline & $\mathrm{R}^{2}\left(\mathrm{R}_{\text {adj }}^{2}\right)$ & \multicolumn{7}{|c|}{$.080(.074)$} \\
\hline & $\mathrm{F}_{(3,517)}$ & \multicolumn{7}{|c|}{$14.92^{* * *}$} \\
\hline
\end{tabular}

Note. ${ }^{*} \mathrm{p}<.05,{ }^{* *} \mathrm{p}<.01,{ }^{* * *} \mathrm{p}<.001$

Table 6

Multiple Regressions with the Interaction Effect for Females

\begin{tabular}{|c|c|c|c|c|c|c|c|c|}
\hline Model 4 & & $\mathrm{~b}$ & $\mathrm{SE}$ & $\beta$ & $\mathrm{t}$ & $p$ & Tolerance & VIF \\
\hline Online & (constant) & $1.543^{-}$ & .617 & & -2.502 & .013 & & \\
\hline \multicolumn{9}{|c|}{ Harassment } \\
\hline & Low self-control & .242 & .049 & .221 & 4.976 & .000 & .993 & 1.007 \\
\hline & Opportunity & .099 & .125 & .035 & .792 & .429 & .987 & 1.014 \\
\hline & LSC * Opportunity & .061 & .032 & .085 & 1.921 & .055 & .994 & 1.006 \\
\hline & $\mathrm{R}^{2}\left(\mathrm{R}_{\text {adj }}^{2}\right)$ & \multicolumn{7}{|c|}{$.058(.052)$} \\
\hline & $\mathrm{F}_{(3,480)}$ & \multicolumn{7}{|c|}{$9.85^{* * *}$} \\
\hline
\end{tabular}

Note. ${ }^{*} \mathrm{p}<.05,{ }^{* *} \mathrm{p}<.01,{ }^{* * *} \mathrm{p}<.001$ 


\section{DISCUSSION}

Developing Internet technology has increased the rates of youth online harassment. This technology provides individuals with more opportunities for deviant behavior (Donner et al., 2014; Power, 2000; Rogers et al., 2006; Ziyanak, 2014). Finn (2004) found that roughly $10 \%$ to $15 \%$ of college students in her study have experienced online harassment. According to a national survey (Jones et al., 2013), the rates of youth online harassment have increased from $6 \%$ in 2000 to $11 \%$ in 2010. The rate of 2009 data from the Korean Institute of Criminology (KIC) (Choi, 2009), which this study used, showed that $35.5 \%$ of respondents have committed online harassment over the last six months compared to illegal downloading (31.2\%), stealing game items or cyber-money from someone (4.9\%), and spreading bad rumors (4.7\%).

Much research has shown the association between the Gottfredson and Hirschi's (1990) self-control theory and online deviance and crime (Buzzell et al., 2006; Donner et al., 2014; Higgins, 2005, 2006; Higgins et al., 2006, 2007; Higgins et al., 2008; Holt et al., 2012; Kim \& Kim, 2014; Moon et al., 2010; Moon et al., 2012), but this research has focused on illegal downloading. The theory has demonstrated a variety of deviances and crimes; for example, low self-control was linked to various online behaviors such as threatening/insulting others through email or instant messaging, hacking into an unauthorized area of the internet, and using someone else's personal information on the internet without his/her permission (Donner et al., 2014). Finally, Gottfredson and Hirschi's (1990) self-control theory provided a useful theoretical framework for this study, and the results of this study strongly supported Gottfredson and Hirschi (1990)'s theory, but other models divided by gender only partially supported interacting effects.
In this study, there are five main findings related to low self-control, opportunity, gender, moderation between low self-control and opportunity, and different models for gender. First, adolescents with low self-control are more likely to commit online harassment than those with high self-control. This result strongly supports Gottfredson and Hirschi's theory; adolescents with high self-control were less likely to commit online deviance and crime (Buzzell et al., 2006; Donner et al., 2014; Higgins, 2005; Holt et al., 2012; Moon et al., 2012).

Second, online harassment was significantly associated to opportunity, especially parental control of time using computer. Despite definition issues of opportunity in the general theory of crime (Higgins \& Ricketts, 2004; Seipel \& Eifler, 2010), this study used opportunity defined by parental control. The reason is that parental control was presented as a control variable for delinquent opportunity (LaGrange \& Silverman, 1999). Many studies also have found that online deviant behaviors were negatively related to parental controls (Eastin et al., 2006; Ybarra et al., 2007).

Third, this study indicated that gender was the most significant factor to online harassment compared to low self-control and opportunity. Buzzell et al. (2006) found that gender was the most significant factor to Internet behaviors. Moon et al. (2012) found that female youths committed less computer crime behaviors than male youths. The result of this study also showed that male adolescents were more likely to commit online harassment than female adolescents. Although gender difference sometimes had mixed results with some behaviors (Higgins, 2006), many studies found the existence of gender difference in other online deviant behaviors (Higgins et al., 2007; Hinduja 2008; Malin \& Fowers, 2009; Morris \& Higgins, 2009). 
Fourth, this study conducted the analysis of interaction between low self-control and opportunity, in particular if the interaction might have an influence on online harassment. Gottfredson and Hirschi (1990) suggested that individuals with low self-control are more likely to engage in various types of deviant and criminal behaviors than those with high selfcontrol, especially when presented with opportunity (Gottfredson \& Hirschi, 1990). This study found that adolescents who are impulsive, insensitive, short-sighted, and risktaking are more likely to commit crime with less opportunity (less parental control of computer using time). That is, the lower selfcontrol and the higher opportunities adolescents have, the more they commit online harassment. While Pratt and Cullen (2000) claimed that opportunity did not work well as a moderating predictor of deviance and crime, this study found the moderating effect between low self-control and opportunity on online harassment similar to previous research (LaGrange \& Silverman, 1999; Longshore \& Turner, 1998; Moon \& Alarid, 2015; Seipel \& Eifler, 2010; Smith, 2004).

Finally, this study analyzed how gender differences with self-control and opportunity impact online harassment. Gender differences in the general theory of crime are still contested. Higgins (2006) noted that many researchers have found mixed results concerning low self-control explaining gender differences. While Tittle et al. (2003) showed that low self-control could account for the gender difference, Longshore et al. (1996) asserted that low self-control should not explain gender differences with offenses. Moon et al. (2012) suggested distinctive findings that some factors about opportunity differently impacted illegal downloading across gender. For example, hours of computer usage increase illegal downloading for boys, while the opportunity factor did not have any significant effect for girls (Moon et al., 2012).

Online harassment is another technologically enabled criminal activity. While generally relegated to the lower tier of offenses, often misdemeanors, the psychological impact where a child is the target of the online harassment may be significant (Finkelhor et al., 2000). In some cases, this has led to suicide among volatile and confused youth (Van Geel et al., 2014).

Where online harassment takes place through methods of obfuscation, the investigative resources needed may not be justified for an apparent misdemeanor absent a particularly terrible outcome, such as a child suicide. But by defining indicia of likely offenders, an investigator/digital forensics examiner may be able to triage targets for investigation, enabling them to more efficiently use resources against such online misconduct. When combined with computationally enabled forensic tools, this may go further to pinpoint more likely potential offenders.

With the expansion and maturation of computer mediated criminal investigation in the use of digital forensics against online misconduct, professionals within the discipline should be called upon for advice and guidance on policies to help prevent and remediate such misconduct. As the study indicates, low selfcontrol combined with opportunity creates a risk of misconduct. This may indicate a heightened attention to issues of low selfcontrol in youth and the need for services to help as well as, possibly, heightened oversight. School, social, and parental policies to reduce opportunity and the risk it creates for online misconduct should also be considered to both deter the offender (reducing the damage that inflicts on the offender herself) and protect possible victims and their psychological and emotional well-being. 
Lastly, the pursuit of justice is more than simply establishing the guilt of a party. Establishing a just and fair sentence for misconduct is at the core of a fair system. In the federal system, 18 United States Code $\S$ 3553 sets out the considerations that must take place in establishing that just and fair sentence. Core considerations are the character of the offender and the possibility of rehabilitation. With youth offenders, this is even more critical they are in a highly formative stage where their lives can take many paths, just they foolishly act to injure others. Understanding these fundamental components as they relate to low self-control can aid in creating and fashioning an appropriate sentence which accomplishes one of the key roles in juvenile sentencing, the rehabilitation of the offender. Consideration of these factors within this new world of online misconduct will best assure a safer and better future for everyone.

\section{CONCLUSION}

This study found that low self-control, opportunity, and interaction had a different influence on online harassment depending on gender. In the model for males, adolescents with low self-control were more likely to commit online harassment than those with high self-control. In addition, the less parents controlled computer using time, the more male adolescents committed online harassment. In the model for females, adolescents with low self-control were also more likely to commit online harassment than those with high selfcontrol. However, online harassment was not expected by opportunity in this model. Furthermore, in these models for males and for females, interaction effects between low selfcontrol and opportunity disappeared, contrary to the fourth result, adolescents who are impulsive, insensitive, short-sighted, and risktaking are more likely to commit crime with less opportunity. This is similar to Moon et al.'s (2012), finding that hours of computer usage increase illegal downloading for boys, while the opportunity factor did not have any significant effect for girls. Gottfredson and Hirschi (1990, p. 147) suggested that "gender differences may be due to differences in crime rather than criminality, and that differences in opportunity may account for much of the male-female differences in crime rates." LaGrange and Silverman (1999) described differential socialization that "females tend to be more closely monitored than males throughout childhood. They therefore have fewer opportunities to express their propensities in antisocial actions, even if such propensities exist" (p. 44). Furthermore, these gender differences may come from the definition issue of opportunity (Higgins \& Ricketts, 2004; Seipel \& Eifler, 2010); this study just used one item as opportunity, 'my parent has a strict time rule about computer use, so I can only use the computer during that time period'. To increase the reliability or validity, the opportunity factor must be more clearly defined and measured with more items.

Despite these issues, this study is important because opportunity in the selfcontrol theory has been less examined. Especially, this study found that opportunity worked as a moderating predictor of online harassment, unlike previous mixed results. Thus, future studies need to include opportunity in the test of self-control theory. Additionally, this study strongly supported Gottfredson and Hirschi (1990)'s theory, but other models divided by gender only partially supported interacting effects. In conclusion, low self-control, the main concept of the theory, is a strong predictor of online harassment in all models of this study. For sturdier models, future studies need to clearly define opportunity and to figure out the cause of gender difference in online harassment. These can, in turn, offer ways to aid in the 
investigation and remediation of this particular

form of digital crime. 


\section{REFERENCES}

Arneklev, B. J., Grasmick, H. G., Tittle, C. R., \& Bursik, R. J. (1993). Self-control theory and imprudent behavior. Journal of Quantitative Criminology, 9, 225-247.

Buzzell, B., Foss, D., \& Middleton, Z. (2006). Explaining use of online pornography: A test of self-control theory and opportunities for deviance. Journal of Criminal Justice and Popular Culture, 13(2), 96-116.

Choi, S. (2009). A study of cybercrime among juveniles. Seoul, Korea: Korean Institute of Criminology.

Cochran, J. K., Wood, P. B., Sellers, C. S., Wilkerson, W., \& Chamlin, M. B. (1998). Academic dishonesty and low self-control: An empirical test of a general theory of crime. Deviant Behavior, 19, 227-255.

Desmond, S. A., Bruce, A. S., \& Stacer, M. J. (2012). Self-control, opportunity, and substance use. Deviant Behavior, 33, 425447.

Donner, C. M., \& Jennings, W. G. (2014). Low self-control and police deviance: Applying Gottfredson and Hirschi's general theory to officer misconduct. Police Quarterly, 17, 203-225.

Donner, C. M., Marcum, C. D., Jennings, W. G., Higgins, G. E., \& Banfield, J. (2014). Low self-control and cybercrime: Exploring the utility of the general theory of crime beyond digital piracy. Computers in Human Behavior, 34, 165-172.

Eastin, M. S., Greenberg, B. S., \& Hofschire, L. (2006). Parenting the Internet. Journal of Communication, 56(3), 486-504.

Finkelhor, D., Mitchell, K. J., \& Wolak, J. (2000). Online victimization: A report on the nation's youth. Alexandria, VA: National Center for Missing and Exploited Children.

Finn, J. (2004). A survey of online harassment as a University campus. Journal of Interpersonal Violence, 19, 468-483.

Fletcher, A., Steinberg, L., \& WilliamsWheeler, M. (2004). Parental influences on adolescent problem behavior: Revisiting Stattin and Kerr. Child Development, $75(3), 781-796$.

Gibson, C., \& Wright, J. (2001). Low selfcontrol and coworker delinquency: A research note. Journal of Criminal Justice, 29, 483-492.

Giles, D. C. (2006). Constructing identities in cyberspace: The case of eating disorders. British Journal of Social Psychology, 45, 463-477.

Gottfredson, M., \& Hirschi, T. (1990). A general theory of crime. Stanford, CA: Stanford University Press.

Hay, C., \& Forrest, W. (2008). Self-control theory and the concept of opportunity: The case for a more systematic union. Criminology, 46(4), 1039-1072.

Higgins, G. E. (2005). Can low self-control help understand the software piracy problem? Deviant Behavior: An Interdisciplinary Journal, 26, 1-24.

Higgins, G. E. (2006). Gender differences in software piracy: The mediating roles of self-control theory and social learning theory. Journal of Economic Crime Management, 4, 1-30.

Higgins, G. E., Fell, B. D., \& Wilson, A. L. (2006). Digital piracy: Assessing the 
contributions of an integrated self-control theory and social learning theory using structural equation modeling. Criminal Justice Studies, 19, 3-22.

Higgins, G. E., Fell, B. D., \& Wilson, A. L. (2007). Low self-control and social learning in understanding students' intentions to pirate movies in the United States. Social Science Computer Review, 25, 339-357.

Higgins, G. E., \& Ricketts, M. L. (2004). Motivation or opportunity: Which serves as the best mediator in self-control theory? Western Criminology Review, 7(2), 77-96.

Higgins, G. E., Wolfe, S. E., \& Marcum, C. D. (2008). Digital piracy: An examination of three measurements of self-control. Deviant Behavior, 29, 440-460.

Hinduja, S. (2008). Deindividuation and Internet Software Piracy. Cyberpsychology E Behavior, 11(4), 391-398.

Holt, T. J., \& Bossler, A. M. (2009). Examining the applicability of lifestyleroutine activities theory for cybercrime victimization. Deviant Behavior, 30, 1-25.

Holt, T. J., Bossler, A. M., \& May, D. C. (2010). Low self-control, deviant peer associations, and juvenile cyber deviance. American Journal of Criminal Justice, 37(3), 378-395.

Joinson, A. N. (2005). Deviance and the internet: New challenges for social science. Social Science Computer Review, 23(1), 57.

Jones, L. M., Mitchell, K. J., \& Finkelhor, D. (2013). Online harassment in context: Trends from three youth internet safety surveys (2000, 2005, 2010). Psychology of Violence, 3, 53-69.

Khunrana, A., Bleakley, A., Jordan, A. B., \& Romer, D. (2015). The protective effects of parental monitoring and internet restriction on adolescents' risk of online harassment. Journal of Youth Adolescence, 44, 1039-1047.

Kim, J. E., \& Kim, J. H. (2014). Software piracy among Korean adolescents: Lessons from panel data. Deviant Behavior, 36, 705-724.

LaGrange, T. C., \& Silverman, R. A. (1999). Low self-control and opportunity: Testing the general theory of crime as an explanation for gender differences in delinquency. Criminology, 37, 41-72.

Longshore, D., \& Turner, S. (1998). Selfcontrol and criminal opportunity: Crosssectional test of the general theory of crime. Criminal Justice and Behavior, 25, 81-98.

Longshore, D., Turner, S., \& Stein, J. (1996). Self-control in a criminal sample: an examination of construct validity. Criminology, 34, 209-228.

Malin, J., \& Fowers, B. J. (2009). Adolescent self-control and music and movie piracy. Computers in Human Behavior, 25, 718722 .

Moon, B., \& Alarid, L. F. (2015). School bullying, low self-control, and opportunity. Journal of Interpersonal Violence, 30, 839856.

Moon, B., Hwang, H., \& McCluskey, J. D. (2011). Causes of school bullying: Empirical test of a general theory of crime, differential association theory, and general strain theory. Crime \& Delinquency, 57, 849-877.

Moon, B., McCluskey, J. D., \& McCluskey, C. P. (2010). A general theory of crime and computer crime: An empirical test. Journal of Criminal Justice, 38, 767-772.

Moon, B., McCluskey, J. D., McCluskey, C. P., \& Lee, S. (2012). Gender, general 
theory of crime and computer crime: An empirical test. International Journal of Offender Therapy and Comparative Criminology, 57, 460-478.

Morris, R. G., \& Higgins, G. E. (2009). Neutralizing potential and self-reported digital piracy: A multi-theoretical exploration among college undergraduates. Criminal Justice Review, 34, 173-195.

O'Brien, R. M. (2007). A caution regarding rules of thumb for variance inflation factors. Quality \& Quantity, 41(5), 673690. doi: 10.1007/s11135-006-9018-6

Piquero, A., \& Tibbetts, S. (1999). The impact of pre/perinatal disturbances and disadvantaged familial environment in predicting criminal offending. Studies on Crime and Crime Prevention, 8, 52-70.

Power, R. (2000). 2000 CSI/FBI computer crime and security survey. Computer Security Issues and Trends, 6, 1-15.

Pratt, T. C., \& Cullen, F. (2000). The empirical status of Gottfredson and Hirschi's general theory of crime: A metaanalysis. Criminology, 38, 931-964.

Raine, A., Brennan, P., \& Mednick, S. (1994). Birth complications combined with early maternal rejection at age 1year predispose to violent crime at age 18 years. Archives of General Psychiatry, 51, 984-988.

Rogers, M., Smoak, N., \& Liu, J. (2006). Selfreported deviant computer behavior. Deviant Behavior, 27, 245-268.

Seipel, C., \& Eifler, S. (2010). Opportunities, rational choice, and self-control: On the interaction of person and situation in a general theory of crime. Crime $\&$ Delinquency, 56, 167-197.

Smith, T. R. (2004). Low self-control, staged opportunity, and subsequent fraudulent behavior. Criminal Justice and Behavior, 31, 542-563.

Tittle, C. R., Ward, D., \& Grasmick, H. (2003). Self-control and crime/deviance: Cognitive vs. behavioral measures. Journal of Quantitative Criminology, 19, 333-365.

Van Geel, M., Vedder, P., \& Tanilon, J. (2014). Relationship between peer victimization, cyberbullying, and suicide in children and adolescents: A meta-analysis. JAMA Pediatrics, 168, 435-442.

Wolak, J., Mitchell, K., \& Finkelhor, D. (2006). Online Victimization of Youth: 5 Years Later. Alexandria, VA: National Center for Missing \& Exploited Children.

Ybarra, M. L., Diener-West, M., \& Leaf, P. J. (2007). Examining the overlap in Internet harassment and school bullying: Implications for school intervention. Journal of Adolescent Health, 41, 42-50.

Ybarra, M. L. (2004). Linkages between depressive symptomatology and internet harassment among young regular internet users. CyberPsychology \&6 Behavior, 7, 247-257.

Ybarra, M. L., \& Mitchell, K. J. (2004). Youth engaging in online harassment: Associations with caregiver-child relationships, Internet use, and personal characteristics. Journal of Adolescence, 27, 319-336.

Ybarra, M. L., Mitchell, K., Wolak, J., \& Finkelhor, D. (2006). Examining characteristics and associated distress related to Internet harassment: findings from the Second Youth Internet Safety Survey. Pediatrics, 118, 1169-1177.

Ziyanak, S. (2014). Examining the impact of technology in the formation of deviance and social control. International Journal of Humanities and Social Science, 4, 207-210. 